\title{
PROCESSO ALTERNATIVO DE DESACIDIFICAÇÃO DO ÓLEO DA POLPA DA MACAÚBA (Acrocomia aculeata) VISANDO ACOPLAMENTO EM USINAS DE PRODUÇÃO DE BIODIESEL
}

\author{
D. B. REZENDE ${ }^{1}$, M. H. C. ANDRADE ${ }^{1}$ e V. M. D. PASA ${ }^{2}$ \\ ${ }^{1}$ Universidade Federal de Minas Gerais, Departamento de Engenharia Química \\ ${ }^{2}$ Universidade Federal de Minas Gerais, Departamento de Química \\ E-mail: bastos_rezende@hotmail.com
}

\begin{abstract}
RESUMO: A disponibilidade de matéria-prima de baixo custo é o fator chave para a viabilidade econômica na produção de biodiesel. Conjuntamente com a matéria-prima, outros fatores que elevam os custos no processo de transformação do óleo vegetal ou gordura animal em biodiesel por transesterificação alcalina estão associados às etapas de purificação da matéria-prima e dos produtos. A macaúba (Acrocomia aculeata) é uma oleaginosa em foco no Estado de Minas Gerais, cuja atual forma extrativista de obtenção a classifica como matéria-prima de acidez elevada, portanto não apta para a produção de biodiesel por processos convencionais. Propõe-se, neste trabalho, o projeto de uma planta industrial contendo uma etapa alternativa de separação dos ácidos graxos livres do óleo da polpa do fruto da macaúba, tecnicamente viável e ambientalmente correta, visando à adequação desse óleo para a produção de biodiesel por transesterificação etílica via catálise alcalina homogênea. O pré-tratamento é constituído por duas etapas principais: extração líquido-líquido para recuperação dos ácidos graxos livres e esterificação heterogênea para neutralização dos ácidos graxos residuais. Na simulação, $50 \mathrm{~kg} \cdot \mathrm{h}^{-1}$ de óleo de macaúba com acidez de 12,92\% são tratados, alcançando-se 40,8 $\mathrm{kg} \cdot \mathrm{h}^{-1}$ de produto com 0,5\% de acidez. $\mathrm{Na}$ validação em teste de bancada, seguindo-se as mesmas etapas da simulação, alcançou-se um produto com acidez de 0,67\%.
\end{abstract}

PALAVRAS-CHAVE: Macaúba; Esterificação; Desacidificação; Extração líquido-líquido; Simulação de processo.

\section{INTRODUÇÃO}

Temas como aquecimento global, crédito de carbono, emissões veiculares e combustíveis renováveis estão cada vez mais em pauta e têm sido prioridade de pesquisadores em todo o mundo. Sustentabilidade deixou de ser um modismo para virar uma necessidade e a busca por soluções energéticas limpas tem tomado dimensões cada vez maiores. No Brasil, juntamente com o etanol, o biodiesel é um dos biocombustíveis que recebe grande aporte de recursos para pesquisas e desenvolvimentos. 
Com o crescimento mundial da demanda e dos preços dos óleos vegetais, o cultivo e o uso de plantas oleaginosas com alta produtividade de óleo se fazem necessários. Devido a essa necessidade, os investimentos em pesquisa e desenvolvimento em extração e refino de óleos vêm crescendo (Costa, 2012). Além disso, a disponibilidade de matéria-prima de baixo custo é o fator chave para a viabilidade econômica na produção de biodiesel, uma vez que seu impacto no preço final é superior a $85 \%$.

Macaúba é uma palmeira do gênero Acrocomia, família Palmae. Existem quinze diferentes espécies dessas palmeiras, das quais dez são encontradas no Brasil. A espécie Acrocomia aculeata é a de maior dispersão no Estado de Minas Gerais, podendo produzir mais de 20 toneladas de frutos por hectare, desenvolvendo-se bem em regiões de altitudes entre $500 \mathrm{~m}$ e $1000 \mathrm{~m}$, índices pluviométricos inferiores a $1500 \mathrm{~mm}$ e temperaturas entre 15 ${ }^{\circ} \mathrm{C}$ e $35^{\circ} \mathrm{C}$. Em uma população oscilante de 100 a 216 palmeiras por hectare, o rendimento de óleo varia entre $1500 \mathrm{~kg} \cdot \mathrm{ha}^{-1}$ a $5000 \mathrm{~kg} \cdot \mathrm{ha}^{-1}$ (Costa et al., 2009).

O melhor momento de colheita é quando os primeiros frutos começam a cair do cacho. Neste estado inicial, o fruto apresenta grau de maturação ótimo e qualidade adequada para processamento. Quando não são colhidos nesse período, acumulam-se no solo, ficando expostos por longos períodos a micro-organismos que provocam a deterioração dos triacilgliceróis da polpa, produzindo ácidos graxos livres (Luciano et al., 2009).

Em relação ao óleo extraído da polpa do fruto da macaúba, há a predominância de ácidos graxos insaturados, correspondendo a aproximadamente $80 \% \mathrm{~m} / \mathrm{m}$ do total. Destacamse os maiores percentuais do ácido oleico, seguido pelo ácido linoleico. O ácido palmítico é o maior representante dos ácidos graxos saturados, com percentuais próximos a $16 \% \mathrm{~m} / \mathrm{m}$ (Pimenta, 2010).

No processo de refino do óleo, o processo de desacidificação é fundamental, especialmente quando o destino do óleo é a produção de biodiesel pelo método convencional de transesterificação alcalina. Estudos indicam que a acidez máxima aceitável na transesterificação homogênea alcalina é $0,5 \%$ em massa (Santori et al., 2012). Essa etapa é usualmente realizada através de refino químico ou físico. Os ácidos graxos livres podem ser eliminados tanto química (neutralização cáustica) quanto fisicamente (remoção por vapor).

No processo de neutralização cáustica, os ácidos graxos livres são neutralizados por uma base, geralmente o hidróxido de sódio, formando uma borra que deve ser removida por centrifugação. Uma parte do óleo neutro é carregada pela borra, gerando perdas no processo. O óleo neutro deve ser lavado para remoção dos sabões e seco (Antoniassi, 1996).

No refino químico, há a limitação para elevados teores de ácidos graxos livres, que podem causar emulsões e formação de sabão, gerando perdas de óleo neutro na borra (Reiport et al., 2011). Outras desvantagens são a utilização de reagentes químicos, a geração de efluentes como água de lavagens e o elevado investimento devido ao número de centrífugas de neutralização e de lavagem (Antoniassi, 1996). As perdas de óleo neutro, para óleos brutos de milho com teores de ácidos graxos livres entre $8 \%$ e $14 \%$, podem atingir de $15 \%$ a $25 \%$. Em refinarias brasileiras que processam óleos com teores iniciais de ácido de aproximadamente $4 \%$, cerca de $14 \%$ de óleo neutro são perdidos (Rodrigues, 2011). Os ácidos graxos livres possuem elevado valor de mercado e sua neutralizam com adição de 
bases significa a transformação de um coproduto em efluente industrial.

O refino físico consiste na destilação sob arraste de vapor dos ácidos graxos livres, devido à sua maior volatilidade com relação aos triacilgliceróis (Cvengros, 1995). Não há limitação quanto ao teor de ácidos graxos livres, porém demanda-se grande quantidade de energia na operação. O refino físico requer baixas pressões de operação, 3 a $6 \mathrm{mmHg}$, e altas temperaturas, de $220{ }^{\circ} \mathrm{C}$ a $270{ }^{\circ} \mathrm{C}$ (Rodrigues, 2011). Devido às condições de operação, podem ocorrer mudanças na coloração do óleo e até oxidação (Reiport et al., 2011). As principais vantagens desse processo são o maior rendimento de óleo neutro, eliminação da etapa de lavagem e, consequentemente, tratamento de águas residuais e menor investimento (Antoniassi, 1996). A maior desvantagem do refino físico é a produção de um óleo com menor estabilidade oxidativa devida às elevadas temperaturas de destilação. Quando aquecidos, o processo de oxidação dos óleos é acelerado, ocorrendo reações de oxipolimerização, que ocorrem em temperaturas entre $200{ }^{\circ} \mathrm{C}$ e $300{ }^{\circ} \mathrm{C}$, e decomposição termo-oxidativa. Ambas as reações podem ocorrer durante etapas de refino dos óleos (Antoniassi, 1996).

Existem outros processos de desacidificação menos usados que a neutralização cáustica e a destilação. Dentre eles, citam-se o refino em micela, a re-esterificação química ou enzimática, a filtração por membranas, a desacidificação biológica, o fluido supercrítico e a extração líquido-líquido. A extração líquido-líquido é uma operação unitária que consiste na remoção de um componente em solução com um solvente através do seu contato com um segundo solvente. Nessa operação, há a transferência de massa de um solvente para o outro (Perry, 1999). As maiores vantagens da extração líquido-líquido com relação aos métodos tradicionais de desacidificação são a redução da perda de óleo neutro, as condições operacionais brandas (pressão atmosférica e temperaturas ambientes), a não utilização de reagentes químicos, a não geração de efluentes e a recuperação dos ácidos graxos livres, subproduto com bom valor de mercado.

A desacidificação de óleos vegetais por extração líquido-líquido tem apresentado eficiências consideráveis na obtenção de óleos vegetais com baixo teor de ácidos graxos livres. Essa rota se destaca pelo baixo consumo de energia uma vez que é realizada à temperatura ambiente e pressão atmosférica. Além disso, diferentemente do que ocorre no refino químico, na extração líquido-líquido recuperam-se também os ácidos graxos livres, que possuem inúmeras aplicações no mercado (Fré, 2009). Essa técnica é fundamentada na diferença de miscibilidade entre os ácidos graxos livres e os triacilgliceróis no solvente, bem como na diferença do ponto de ebulição entre os líquidos (Navarro et. al., 2007).

A utilização de etanol para extração dos ácidos oleico e linoleico adicionados em amostras de óleo de macaúba neutralizado e degomado foi estudada por Rezende (2009) avaliando-se diferentes concentrações de água no etanol, a $25^{\circ} \mathrm{C}$. Nesse trabalho concluiu-se que a seletividade, parâmetro que avalia a capacidade do solvente em remover preferencialmente o soluto da alimentação, tende a aumentar com a maior concentração de água no solvente, reduzindo a quantidade de óleo na fase alcoólica. De acordo com o autor, isso ocorre devido ao aumento da polaridade do solvente e a consequente repulsão das moléculas de triacilgliceróis, causando menor arraste de óleo para a fase alcoólica. Em contrapartida, o aumento da concentração de água no solvente provoca uma diminuição nos 
valores dos coeficientes de distribuição, indicando que quanto maior a quantidade de água no etanol, menor é a capacidade de o solvente extrair os ácidos graxos livres.

A remoção dos ácidos graxos livres por extração líquido-líquido com etanol também foi avaliada em amostra de óleo de macaúba bruto e com elevado conteúdo de ácidos graxos livres originais do óleo por Rezende (2015), que aproximam os testes realizados neste trabalho com a realidade da indústria. Os resultados obtidos foram similares aos encontrados em trabalhos com a macaúba ou outras fontes de triacilgliceróis, os quais fazem uso de óleos degomados, refinados e neutralizados, com adição de ácidos graxos livres como o ácido oleico. Nesse teste, aguardou-se pela separação de fases por apenas 1 hora, enquanto que em alguns trabalhos consultados, o tempo adotado chega a 12 horas. Através do modelo termodinâmico NRTL (Non-Random-Two-Liquid), baseado no conceito de composição local, os dados experimentais do equilíbrio líquido-líquido foram modelados, chegando-se em erros de $7,06 \%$ e $2,74 \%$ para as extrações com etanol anidro e etanol hidratado, respectivamente.

O modelo NRTL apresenta cinco parâmetros ajustáveis: $A_{i j}, A_{j i}, B_{i j}, B_{j i}$ e $\alpha_{i j}$. Os quatro primeiros estão relacionados à energia característica da interação entre as moléculas do tipo $i$ e $j$. O parâmetro $\alpha$ está relacionado com a não aleatoriedade da mistura. Devido à variedade de componentes presentes nos óleos vegetais e pela facilidade de se trabalhar com frações mássicas, trabalha-se com o conceito de pseudo-componentes, aos quais se atribui uma massa molar média. As equações do modelo NRTL são (Gonçalves e Meirelles, 2004):

$$
\begin{aligned}
& \ln \left(\gamma_{i}\right)=\frac{\sum_{j=1}^{K} \frac{\tau_{j i} G_{j i} W_{j}}{\bar{M}_{j}}}{\sum_{j=1}^{K} \frac{G_{j i} W_{j}}{\bar{M}_{j}}}+\sum_{j=1}^{K}\left[\frac { W _ { j } G _ { j i } } { \overline { M } _ { j } \sum _ { l = 1 } ^ { n } \frac { G _ { l j } W _ { l } } { \overline { M } _ { l } } } \left(\tau_{i j}-\frac{\sum_{l=1}^{K} \frac{\tau_{l j} G_{l j} W_{l}}{\bar{M}_{l}}}{\left.\left.\sum_{l=1}^{K} \frac{G_{l j} W_{l}}{\bar{M}_{l}}\right)\right]}\right.\right. \\
& \tau_{i j}=\frac{\Delta g_{i j}}{R T}=A_{i j}+\frac{B_{i j}}{T} \quad\left(\tau_{i j} \neq \tau_{j i}\right) \\
& G_{i j}=\exp \left(-\alpha_{i j} \tau_{i j}\right) \quad\left(\alpha_{i j}=\alpha_{j i}\right)
\end{aligned}
$$

Onde $W$ é a fração mássica e $M$ é a massa molar de cada pseudo-componente.

A Tabela 1 apresenta os valores dos parâmetros binários obtidos a partir de dados experimentais de equilíbrio líquido-líquido da extração de ácidos graxos livres em óleo de macaúba bruto utilizando-se etanol hidratado $95 \%$ como solvente extrator a $25{ }^{\circ} \mathrm{C}$. Os parâmetros A e B são os parâmetros binários assimétricos determinados pela regressão dos

dados experimentais do modelo NRTL. O parâmetro simétrico $\alpha$ ij foi fixado em 0,3 , valor

normalmente utilizado para misturas de compostos apolares e com pequenos desvios da idealidade (Rezende, 2015): 
Tabela 1 - Parâmetros binários do método NRTL para o sistema triacilgliceróis (1) + ácidos graxos livres (2) + etanol hidratado (3) a $25^{\circ} \mathrm{C}$ (Rezende, 2015).

\begin{tabular}{c|c|c|c|c}
\hline Par $\boldsymbol{i j}$ & $\boldsymbol{A i j}$ & $\boldsymbol{A j i}$ & $\boldsymbol{B i j}(\boldsymbol{K})$ & $\boldsymbol{B j i}(\boldsymbol{K})$ \\
\hline 12 & $-1,5626$ & $-1,4354$ & $-459,6600$ & $-434,4464$ \\
\hline 13 & 12,3999 & 2,9591 & 3696,0835 & 905,6068 \\
\hline 23 & $-1,4166$ & $-3,7982$ & $-387,9721$ & $-1138,1683$ \\
\hline
\end{tabular}

Outra técnica que vem sendo utilizada, sobretudo quando o óleo vegetal se destina à produção de biodiesel, é a esterificação dos ácidos graxos livres. A reação de esterificação consiste na produção de uma molécula de éster alquílico e uma molécula de água a partir da reação de uma molécula de ácido graxo livre e uma molécula de álcool na presença de um catalisador ácido, conforme Figura 1 (Jacobson et al., 2008).<smiles>[2H]C(=O)O</smiles>

Ácido graxo livre<smiles>[CH2+]O</smiles>

Metanol

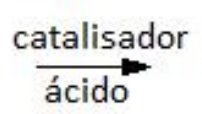<smiles>[R]C(=O)OC</smiles>

Éster alquílico

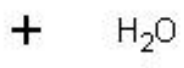

Água

Figura 1 - Reação de esterificação.

Em especial, os catalisadores sólidos têm grande potencial para substituir os líquidos, eliminando processos de separação, corrosão e problemas ambientais (Kulkarni et al., 2006). Etapas de purificação do biodiesel e do glicerol para remoção do catalisador acarretam em custos de produção. Para se tornar economicamente viável e para competir comercialmente com o diesel de petróleo, o processo produtivo do biodiesel deve ser contínuo e ter o menor número de operações de separação e purificação (Lotero et al., 2005).

Em trabalhos realizados utilizando-se a resina cationnica Purolite CT275DR como catalisador heterogêneo ácido na esterificação de ácidos graxos livres presentes em amostras de óleo de macaúba com acidez inicial de 10\% em massa de ácido oleico, chegou-se a uma lei de velocidade com característica de pseudo-primeira ordem com relação à concentração de ácidos graxos livres, com constante média de velocidade de $0,3245 \mathrm{~h}^{-1}$, conforme Equação 2, onde $r_{A}$ está em mol.g ${ }^{-1} \cdot \mathrm{h}^{-1}$ e $C_{A}$ em mol.g ${ }^{-1}$ :

$$
-r_{A}=0,3245 . C_{A}
$$


Não houve tendência de redução da atividade catalítica durante as cinco bateladas. Em amostras com acidez inicial próxima a $10 \%$ em massa de ácido oleico, chegou-se a uma redução de até $96,6 \%$ de ácidos graxos livres. As reações foram conduzidas em um reator rotativo de leito fluidizado, em banho de $85^{\circ} \mathrm{C}$, contendo razão mássica de óleo de macaúba (contendo triacilgliceróis e ácidos graxos livres) e etanol anidro de 1:1, que representa um grande excesso de etanol na reação. A quantidade de resina utilizada foi equivalente a $20 \%$ da massa de óleo e etanol presentes no meio reacional (Rezende et al., 2015).

A resina CT275DR é uma resina catalítica de troca cationica, fortemente ácida, macroporosa, com ácido sulfônico como grupo funcional e substrato polimérico de poliestireno ligado a divinilbenzeno com ligações cruzadas e capacidade de troca iônica maior que 5,20 eq/kg (peso seco) (Rezende et al., 2015).

Nesse sentido, neste artigo é proposto um processo alternativo de desacidificação do óleo de macaúba bruto (não degomado e não refinado) através da recuperação dos ácidos graxos livres por extração líquido-líquido com etanol hidratado $95 \%$ e, em sequência, a esterificação dos ácidos graxos livres remanescentes no óleo de macaúba. Para o dimensionamento de uma operação de extração líquido-líquido, foram utilizados parâmetros de modelagem NRTL obtidos a partir de dados de equilíbrio do sistema pseudo-ternário de óleo de macaúba bruto, ácidos graxos livres provenientes da oxidação do óleo de macaúba e etanol hidratado (Rezende et al., 2015).

$\mathrm{Na}$ etapa de esterificação, os ácidos graxos livres remanescentes no óleo foram esterificados na presença de um catalisador heterogêneo. $O$ catalisador heterogêneo utilizado foi a resina catiônica Purolite CT275DR que, em trabalhos anteriores, apresentou resultados promissores (Rezende, 2015).

\section{MATERIAIS E MÉTODOS}

O processo de pré-tratamento visando acoplamento ao processo de produção de biodiesel foi simulado de forma isolada (extração líquido-líquido e esterificação) a partir dos dados obtidos na literatura e de forma integrada. Para essa simulação, utilizou-se o software ASPEN PLUS 8.4 (para a extração líquido-líquido) e o Microsoft Excel 2010 (para os demais balanços de massa). A partir da simulação, obteve-se o balanço de massa do processo, reciclos, recuperação de insumos, dentre outras informações que tornam o processo tecnicamente viável. Adotou-se uma alimentação de óleo de $50 \mathrm{~kg} \cdot \mathrm{h}^{-1} \mathrm{com}$ acidez inicial de 12,92\% em massa de ácido oleico, valor escolhido devido à disponibilidade de amostra para a realização de teste em bancada para validação da simulação.

Para a etapa de extração líquido-líquido, foram utilizados os parâmetros binários para o modelo NRTL obtidos em ensaios de equilíbrio de fases em amostras de óleo bruto de macaúba com diferentes índices de acidez (de 3,3\% a 31,9\% em massa de ácido oleico) e etanol hidratado a 95\%, conforme Tabela 1. Os parâmetros binários do modelo foram gerados através do software ASPEN PLUS 8.4. Nessa modelagem, o solvente (etanol hidratado), os ácidos graxos livres e os triacilgliceróis do óleo da polpa do fruto da macaúba foram considerados pseudocomponentes, por não se tratarem de substâncias puras (Rezende, 2015). 
Algumas propostas de extrações líquido-líquido foram simuladas com objetivo de se obter um refinado com índice de acidez próximo a 5\%, variando-se o tipo de extração (contracorrente e corrente cruzada) e a quantidade de solvente com relação à alimentação de óleo ácido. Os cálculos foram feitos através do software ASPEN PLUS 8.4. Em todos os casos, considerou-se um sistema pseudo-ternário: triacilgliceróis, ácidos graxos livres e solvente. Cada um desses pseudo-componentes representa um vértice no diagrama ternário de equilíbrio. São chamados de pseudo-componentes por não se tratarem de substâncias puras. Para todas as simulações, adotou-se uma alimentação (triacilgliceróis + ácidos graxos livres) de $50 \mathrm{~kg} \cdot \mathrm{h}^{-1} \mathrm{com} 12,92 \%$ de acidez em massa de ácido oleico.

A lei de velocidade utilizada nesse trabalho descrita pela Equação 2 foi obtida através de cinco ensaios em batelada com amostras de óleo bruto de macaúba com acidez variando de $8,5 \%$ a $12,8 \%$. As reações foram realizadas na temperatura em banho a $85^{\circ} \mathrm{C}$, garantindo a ebulição e refluxo do etanol no meio reacional. A quantidade de catalisador utilizada foi de $20 \%$ da soma das massas de óleo e de etanol e o tempo total de cada reação foi de 8 horas, com amostragem a cada 1 hora de reação. A razão em massa utilizada de etanol/óleo foi de 1:1 (Rezende et al., 2015).

Devido à sensibilidade da resina ao choque mecânico, a reação não pôde ser realizada sob agitação mecânica com impelidor ou agitação magnética. Assim, a reação foi realizada em um equipamento do tipo rotavapor (FISATOM), cujo condensador e o balão coletor de condensado foram substituídos por um condensador reto com circulação de água. Foi utilizada uma rotação de aproximadamente $100 \mathrm{rpm}$ em todos os ensaios. Esse sistema reacional é referido como Reator Rotativo, sendo apresentado na Figura 2 (Rezende et al., 2015). 


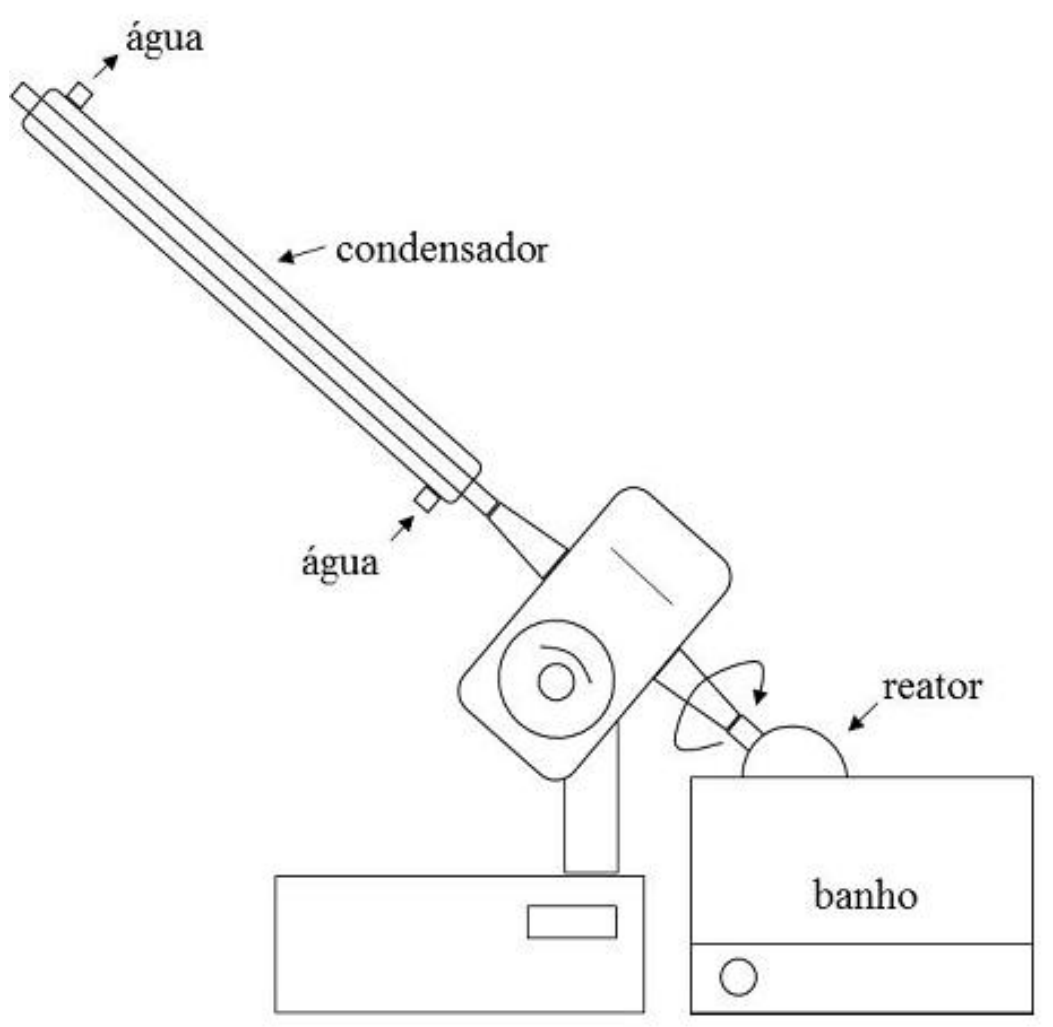

Figura 2 - Esquema do reator rotativo utilizado nas reações de esterificação (Rezende et al., 2015).

Neste trabalho, realizou-se o dimensionamento de reatores contínuos baseando-se em reatores CSTR (reatores de tanques agitados contínuos). Trata-se de um modelo de reator contínuo ideal, no qual se considera que a composição de saída do reator é idêntica à composição interna do mesmo (Fogler, 2002). A velocidade de reação é avaliada nas condições de saída através da lei de velocidade da reação de esterificação. Para o dimensionamento, foram consideradas as seguintes informações:

- Concentração inicial de ácidos graxos livres na alimentação de óleo: 5,0\% em massa de ácido oleico $\left(1,77 \times 10^{-4} \mathrm{~mol} / \mathrm{g}\right.$ ou $1,63 \times 10^{-4} \mathrm{~mol} / \mathrm{cm}^{3}$ considerando a densidade do óleo como $\left.0,92 \mathrm{~kg} . \mathrm{L}^{-1}\right)$. Pretende-se alimentar o reator com o refinado da operação de extração líquido-líquido.

- Concentração final de ácidos graxos livres na fase óleo: 0,5\% em massa de ácido oleico $\left(1,77 \times 10^{-5} \mathrm{~mol} / \mathrm{g}\right.$ ou $1,63 \times 10^{-5} \mathrm{~mol} / \mathrm{cm}^{3}$ considerando a densidade do óleo como 0,92 $\left.\mathrm{kg} . \mathrm{L}^{-1}\right)$. O valor de $0,5 \%$ foi adotado por ser um valor de acidez aceitável na matériaprima para produção de biodiesel por transesterificação alcalina convencional.

- Alimentação de óleo (triacilgliceróis + ácidos graxos livres) de 50 kg.h $\mathrm{h}^{-1}$ (47,5 kg.h $\mathrm{h}^{-1} \mathrm{de}$ triacilgliceróis e $2,5 \mathrm{~kg} \cdot \mathrm{h}^{-1}$ de ácidos graxos livres).

Define-se a conversão, $X$, como a razão entre o número de moles de ácidos graxos 
livres reagidos e o número de moles de ácidos graxos livres na alimentação (Fogler, 2002). A partir dos valores de acidez na entrada, $5 \%$, e na saída do reator, $0,5 \%$, chega-se à conversão de $90 \%$. O volume necessário para se atingir a conversão desejada em um reator CSTR é dada pela seguinte equação de projeto (Fogler, 2002):

$$
V=\frac{F_{A 0} X}{-r_{A}}
$$

Onde $F_{A 0}$ é a vazão molar de ácidos graxos livres na alimentação, $X$ é a conversão desejada e $-r_{A}$ é a velocidade de desaparecimento dos ácidos graxos livres avaliada nas condições de saída do reator, definida através da Lei de Velocidade.

As etapas de extração líquido-líquido e de esterificação definidas na simulação do processo foram reproduzidas em bancada para validação do modelo. Para os testes, foram adotadas as mesmas condições operacionais utilizadas para o levantamento de dados do equilíbrio líquido-líquido e da lei de velocidade da reação de esterificação. A acidez das amostras foi determinada através de titulação ácido-base (AOCS Cd3d-63.10) e o teor de solvente por perda por evaporação ( $2 \mathrm{~g}$ de amostra em estufa com circulação de ar a $80{ }^{\circ} \mathrm{C}$ por 60 minutos).

\section{RESULTADOS E DISCUSSÃO}

\subsection{Extração Líquido-Líquido}

A Tabela 2 apresenta dados simulados de extração líquido-líquido utilizando como solvente o etanol hidratado, calculadas utilizando o modelo termodinâmico NRTL e o software ASPEN PLUS 8.4.

Tabela 2 - Extrações líquido-líquido em corrente cruzada para o sistema com etanol hidratado com alimentação de óleo com $12,92 \%$ de acidez.

\begin{tabular}{c|c|c|c|c}
\hline $\begin{array}{l}\text { Razão mássica alimentação/solvente } \\
\text { por estágio }\end{array}$ & $\begin{array}{l}\text { Perda de } \\
\text { triacilglicerol na } \\
\text { fase extrato (\%) }\end{array}$ & $\begin{array}{l}\text { Índice de acidez do } \\
\text { refinado em base } \\
\text { livre de solvente (\%) }\end{array}$ \\
\hline $\mathbf{1}^{\mathbf{o}}$ Estágio & $\mathbf{2}^{\mathbf{0}}$ Estágio & $\mathbf{3}^{\mathbf{o}}$ Estágio & 12,78 & 3,77 \\
\hline 1 & 1 & 1 & 11,92 & 4,10 \\
\hline 1,5 & 1 & 1 & 11,80 & 4,06 \\
\hline 1 & 1,5 & 1 & 11,79 & 4,06 \\
\hline 1 & 1 & 1,5 & 10,90 & 4,45 \\
\hline 1,5 & 1,5 & 1 & 10,89 & 4,44 \\
\hline 1,5 & 1 & 1,5 & 10,76 & 4,40 \\
\hline 1 & 1,5 & 1,5 & 9,82 & 4,85 \\
\hline 1,5 & 1,5 & 1,5 & 11,38 & 4,35 \\
\hline 2 & 1 & 1 & 11,25 & 4,26 \\
\hline 1 & 2 & 1 & 11,27 & 4,25 \\
\hline 1 & 1 & 2 & 9,76 & 5,04 \\
\hline 2 & 2 & 1 & & \\
\hline
\end{tabular}




\begin{tabular}{l|l|l|l|l}
\hline 2 & 1 & 2 & 9,76 & 4,98 \\
\hline 1 & 2 & 2 & 9,63 & 4,88 \\
\hline 2 & 2 & 2 & 7,91 & 5,92 \\
\hline 2,5 & 1 & 1 & \multicolumn{2}{|l}{ Não houve separação de fases } \\
\hline 1 & 2,5 & 1 & 10,91 & 4,41 \\
\hline 1 & 1 & 2,5 & 10,95 & 4,39 \\
\hline 1 & 2,5 & 2,5 & 8,87 & 5,27 \\
\hline 2,5 & 2,5 & 1 & \multicolumn{4}{|l}{ Não houve separação de fases } \\
\hline 2,5 & 1 & 2,5 & \multicolumn{2}{|l}{ Não houve separação de fases } \\
\hline 2,5 & 2,5 & 2,5 & \multicolumn{3}{|c}{ Não houve separação de fases } \\
\hline
\end{tabular}

Nas configurações em contracorrente, não houve convergência dos dados utilizando-se o máximo de iterações permitidas pelo software. As únicas condições na configuração em contracorrente nas quais houve convergência foram para valores de acidez na alimentação inferiores a $12 \%$. Portanto, avaliou-se somente a configuração de corrente cruzada. Em análise dos dados da Tabela 2, confirma-se a redução da seletividade com o aumento da concentração de ácidos graxos livres na alimentação. Esse fato é evidenciado pela perda de triacilglicerol no extrato que aumenta com o aumento da acidez na alimentação. As perdas também se elevam com o aumento da quantidade de solvente utilizada em cada etapa.

Observa-se que nas extrações com razão mássica alimentação/solvente de 2,5 no primeiro estágio não houve separação de fases. Nesta razão, a mistura global passa a ter um teor de ácidos graxos livres muito elevado, fazendo com que a mistura caia na região totalmente miscível no diagrama ternário.

Com 12,92\% de índice de acidez, a desacidificação possui perdas de óleo neutro comparáveis aos métodos físicos e químicos. Nas simulações em corrente cruzada, foram avaliadas quantidades diferentes de solventes em cada estágio de extração. Na medida em que se diminui a quantidade de solvente, mais etapas são necessárias para se atingir o índice de acidez desejado. A redução da quantidade de solvente gera menor perda de triacilgliceróis por estágio. Porém, como consequência da redução do solvente, mais estágios se fazem necessários para se atingir um refinado com o índice de acidez desejada, e cada estágio de extração gera uma perda de triacilgliceróis. Logo, deve-se encontrar um equilíbrio entre a quantidade de solvente utilizada e a quantidade de estágios necessária.

Para a simulação da planta piloto e reprodução em laboratório, será considerada a alimentação com $12,92 \%$ de acidez e três estágios de extração líquido-líquido com relação mássica alimentação/solvente de 1, 1 e 2,5 em cada estágio, respectivamente, por apresentar baixo valor de acidez no refinado e baixa perda de triacilglicerol no extrato.

\subsection{Esterificação}

$\mathrm{Na}$ determinação do volume do reator, como a lei de velocidade, $-r_{A}$, foi determinada para a concentração de ácidos graxos em base livre de etanol, deve-se calcular também o volume necessário para a alimentação do etanol, que será alimentada sempre na proporção de 1:1 em massa com relação à alimentação de óleo (triacilgliceróis + ácidos graxos livres). 
Além disso, deve-se considerar a presença do catalisador no reator, equivalente a $20 \%$ da massa dos reagentes. Para os cálculos, as densidades do etanol e da resina catiônica utilizadas serão de $0,79 \mathrm{~kg} . \mathrm{L}^{-1}$ e $1,2 \mathrm{~kg} . \mathrm{L}^{-1}$, respectivamente (Rezende, 2015). Por fim, será acrescentado $20 \%$ de volume ao valor calculado, como fator de segurança. A Tabela 3 apresenta os resultados dos volumes calculados considerando-se um reator CSTR.

Tabela 3 - Volume do CSTR para conversão de 90\% dos ácidos graxos livres nas condições pré-definidas.

\begin{tabular}{|c|c|c|c|c|}
\hline $\begin{array}{c}\text { Volume } \\
\text { necessário } \\
\text { para a } \\
\text { alimentação } \\
\text { de óleo }(L)\end{array}$ & $\begin{array}{c}\text { Volume } \\
\text { necessário } \\
\text { para a } \\
\text { alimentação } \\
\text { de etanol (L) }\end{array}$ & $\begin{array}{c}\text { Volume } \\
\text { necessário } \\
\text { para o } \\
\text { catalisador } \\
\text { (L) }\end{array}$ & $\begin{array}{l}\text { Volume total } \\
\text { (L) }\end{array}$ & $\begin{array}{c}\text { Volume } \\
\text { considerando } \\
20 \% \text { como } \\
\text { margem de } \\
\text { segurança }(L)\end{array}$ \\
\hline 1276 & 1486 & 391 & 3153 & 3783 \\
\hline
\end{tabular}

$\mathrm{O}$ volume de reator pode ser reduzido utilizando-se reatores CSTR em série. As Figuras 3 e 4 apresentam, de forma qualitativa, uma comparação entre os volumes necessários para a conversão desejada no caso de um CSTR e dois CSTRs em série, respectivamente. $\mathrm{O}$ volume necessário é proporcional à área hachurada em cada gráfico. Verifica-se que a Figura 4 possui duas áreas hachuradas, equivalentes a dois reatores CSTRs em série. Os cálculos são semelhantes aos utilizados em um único reator. Porém, a alimentação do segundo reator é o produto do primeiro. Da mesma forma, a conversão, $X$, utilizada no cálculo do volume do segundo reator é conversão final desejada menos a conversão alcançada no primeiro reator.

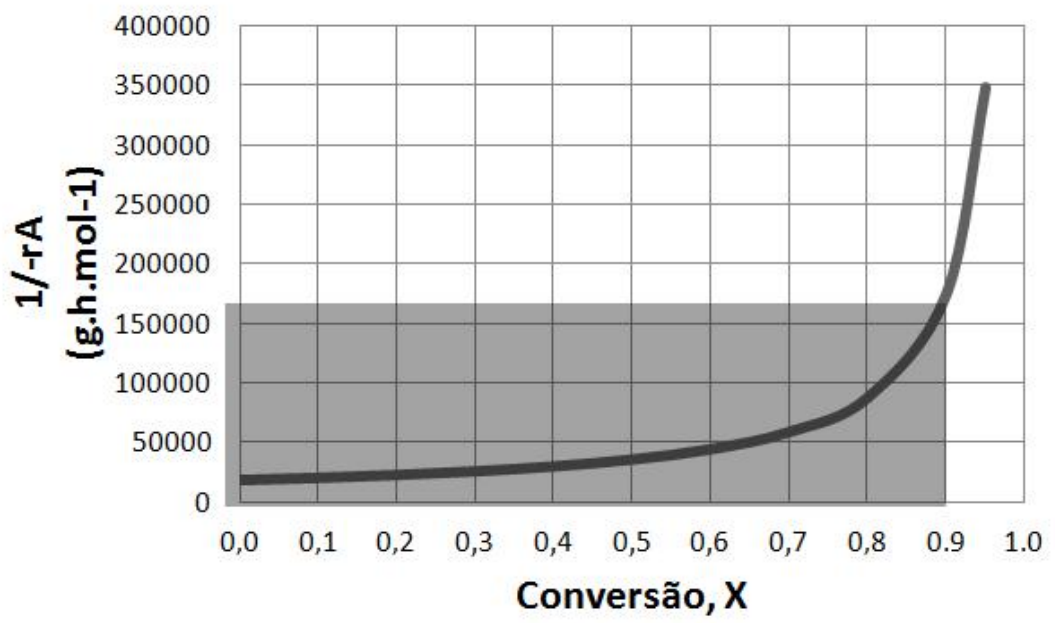

Figura 3 - Representação qualitativa da área necessária para a conversão desejada em um CSTR. 


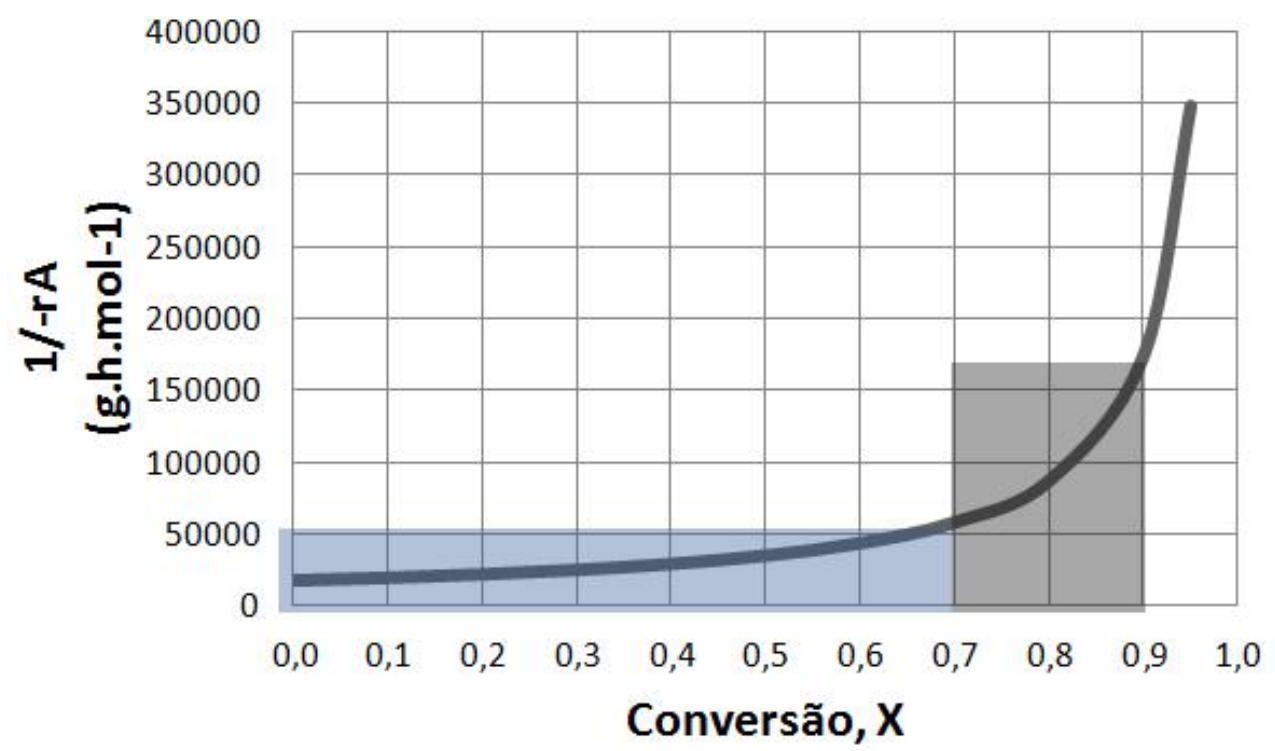

Figura 4 - Representação qualitativa das áreas necessárias para a conversão desejada em dois CSTRs em série.

A Tabela 4 apresenta os resultados dos volumes calculados considerando-se dois reatores CSTR.

Tabela 4: Volume dos dois CSTRs para conversão de 90\% dos ácidos graxos livres nas condições pré-definidas.

\begin{tabular}{|c|c|c|c|c|c|}
\hline CSTR & $\begin{array}{c}\text { Volume } \\
\text { necessário } \\
\text { para a } \\
\text { alimentação } \\
\text { de óleo (L) }\end{array}$ & $\begin{array}{c}\text { Volume } \\
\text { necessário } \\
\text { para a } \\
\text { alimentação } \\
\text { de etanol (L) }\end{array}$ & $\begin{array}{c}\text { Volume } \\
\text { necessário } \\
\text { para o } \\
\text { catalisador } \\
\text { (L) }\end{array}$ & $\begin{array}{l}\text { Volume } \\
\text { total (L) }\end{array}$ & $\begin{array}{c}\text { Volume } \\
\text { considerando } \\
20 \% \text { como } \\
\text { margem de } \\
\text { segurança } \\
\text { (L) }\end{array}$ \\
\hline 1 & 331 & 385 & 391 & 1107 & 1328 \\
\hline 2 & 284 & 330 & 391 & 1005 & 1206 \\
\hline Total & 615 & 715 & 782 & 2112 & 2534 \\
\hline
\end{tabular}

Verifica-se que o volume total dos dois CSTRs em série é aproximadamente $65 \%$ do volume considerando-se um único CSTR. A opção por dois CSTRs é interessante por dar 
mais flexibilidade ao projeto, abrindo possibilidades de alimentações em paralelo ou em série, redução de capacidade da planta, dentre outras possíveis situações.

\subsection{Simulação do Processo}

Nesta seção, fez-se uma proposta de uma planta de pré-tratamento de óleo vegetal com acidez de 12,92\% em massa de ácido oleico com capacidade de processamento de $50 \mathrm{~kg} \cdot \mathrm{h}^{-1}$. $\mathrm{Na}$ etapa de extração líquido-líquido, foi considerada a operação em corrente cruzada e três estágios com relações mássicas óleo/solvente de 1;1 e 2,5 em cada estágio, respectivamente. Para a simulação da extração líquido-líquido, utilizou-se o software ASPEN PLUS 8.4 com os parâmetros NRTL já determinados anteriormente para a utilização de etanol hidratado como solvente de extração. A Figura 5 apresenta essa configuração da forma como foi inserida no software, na qual EXTR1, EXTR2 e EXTR3 representam estágios da operação de extração líquido-líquido, $T Q$ representa um tanque para recebimento das três correntes de extrato, $F$ é a alimentação do primeiro estágio juntamente com o etanol hidratado, $R 1, R 2$ e $R$ são as correntes dos refinados do primeiro, segundo e terceiro estágios, respectivamente, $E 1$, $E 2$ e $E 3$ são as correntes de extrato dos três estágios, $E$ é a soma dos três extratos e $S 2$ e $S 3$ são as entradas de solventes nos estágios 2 e 3 .

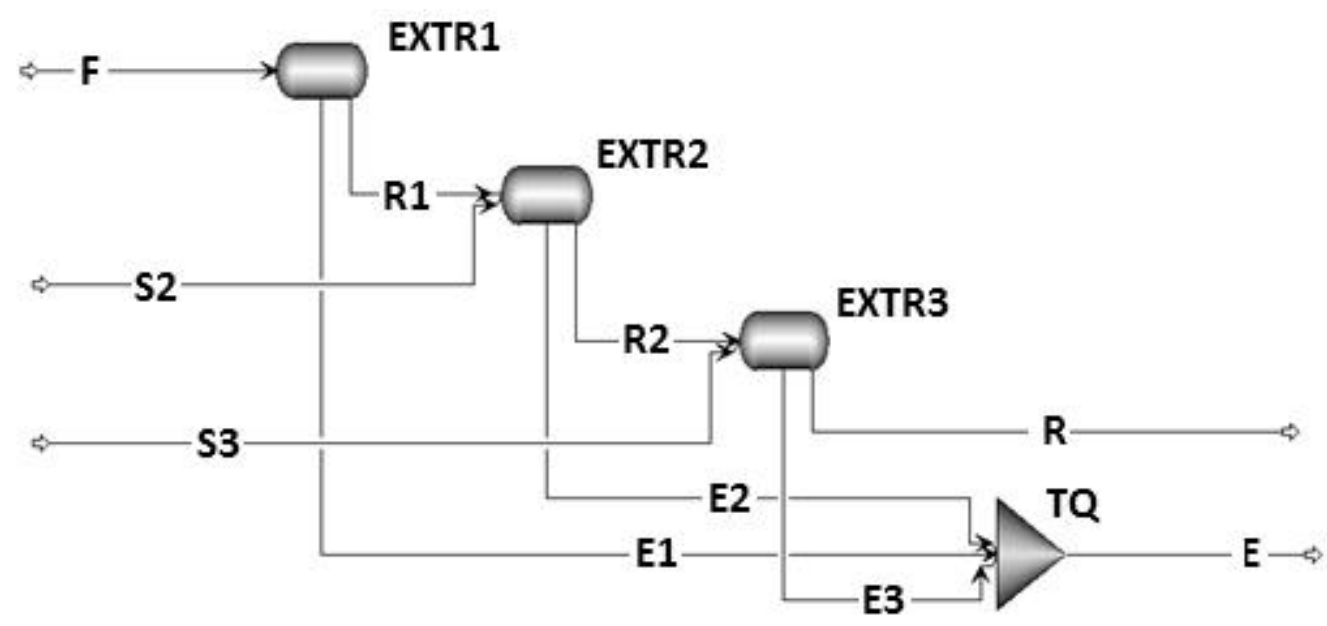

Figura 5 - Operação de extração líquido-líquido em três estágios em corrente cruzada.

Para a etapa de esterificação, considerou-se a lei de velocidade apresentada na Equação 2. Para validação dos balanços realizados através do modelo termodinâmico de extração líquido-líquido e da lei de velocidade para esterificação, realizou-se uma produção em bancada, seguindo-se os mesmos parâmetros e configurações propostos na planta de prétratamento. Como alimentação, foi utilizada uma amostra de óleo da polpa da macaúba com acidez inicial de $12,92 \%$ em massa de ácido oleico.

Foram feitas algumas considerações a fim de simplificar o balanço de massa:

- Considerou-se $277 \mathrm{~g} / \mathrm{mol}$ como a massa molar média ponderada dos ácidos graxos livres, baseando-se na fração de massa dos ácidos graxos presentes (Rezende, 2015). 
- Considerou-se $291 \mathrm{~g} / \mathrm{mol}$ como a massa molar média ponderada dos ésteres alquílicos formados na esterificação, baseando-se na fração em massa de ácidos graxos presentes no óleo da polpa da macaúba (Rezende, 2015).

- O tempo de residência dos regentes na operação de esterificação foi o suficiente para se alcançar um produto com acidez de $0,50 \%$ em base livre de solvente.

- Considerou-se, nas operações de destilação, uma eficiência de 100\%.

- Considerou-se perda zero em todo o processo.

- Considerou-se que toda a água presente no solvente deixa a operação de extração líquidolíquido na corrente do extrato. Apesar de o extrato não conter toda a água presente no solvente, essa consideração é razoável e encontra suporte em resultados experimentais de extração líquido-líquido com óleo de macaúba (Rezende, 2009).

- Na simulação, utilizou-se uma alimentação com o mesmo índice de acidez que a amostra utilizada na produção em bancada: $12,92 \%$ em massa de ácido oleico.

A Figura 6 apresenta o processo proposto, contendo as correntes principais, reciclos de etanol e balanço de massa considerando-se uma alimentação de $50 \mathrm{~kg} \cdot \mathrm{h}^{-1}$ de óleo ácido com acidez de $12,92 \%$.

Nesse processo, o refinado chega à etapa de esterificação com acidez de 4,8\%. De acordo a lei de velocidade utilizada nesse trabalho, seria necessário um tempo de residência mínimo de 7 horas para se conseguir uma conversão de ácidos graxos livres em ésteres alquílicos suficiente para se obter um óleo com acidez inferior a $0,5 \%$ em massa de ácido oleico em base livre de solvente. Esse valor é considerado aceitável para a utilização do óleo como matéria-prima para a produção de biodiesel.

Em uma análise global, verifica-se que há apenas $11 \%$ de perda de óleo neutro na extração líquido-líquido, valor comparável aos métodos atuais de refino químico e físico. Porém, no processo proposto, os triacilgliceróis não sofrem com condições operacionais extremas, como as utilizadas no refino físico e não há geração de efluentes, utilização de catalisadores homogêneos e consumo de reagentes alcalinos, como no refino químico. Além disso, os ácidos graxos livres, que possuem valor no mercado, não são perdidos no processo.

Outro fator positivo do processo é que o único reagente utilizado é o etanol na operação de esterificação, álcool proveniente de fontes renováveis com alto volume de produção no Brasil. Esse fato, associado às condições moderadas de operação (pressão ambiente e baixas temperaturas), contribuem para uma produção ambientalmente correta, com baixa emissão de carbono, baixa geração de efluente, baixo consumo de água, dentre outras vantagens ecológicas.

\subsection{Validação da Simulação através de Testes de Bancada}

$\mathrm{Na}$ produção em bancada foram realizadas as mesmas etapas descritas no processo proposto, conforme fluxograma da Figura 6. A amostra de óleo de macaúba com acidez 
inicial de $12,92 \%$ foi submetida a três estágios de extração líquido-líquido nas mesmas condições operacionais utilizadas na simulação computacional. A mistura da alimentação e do solvente (etanol hidratado) foi realizada em um agitador mecânico por 30 minutos e a separação de fases realizada em um funil de separação por 1 hora. Esse procedimento foi realizado por três vezes, representando os três estágios de extração líquido-líquido, com relação mássica óleo/solvente nos três estágios, respectivamente, de $1 ; 1$ e 2,5.

A Tabela 5 apresenta um comparativo entre os resultados estimados através da simulação computacional para a extração líquido-líquido e os resultados obtidos na produção em bancada.

Tabela 5 - Comparação entre as correntes simuladas e da produção em bancada da extração líquido-líquido.

\begin{tabular}{|c|c|c|c|c|c|}
\hline \multirow{2}{*}{\multicolumn{2}{|c|}{ Corrente }} & \multicolumn{2}{|c|}{ Simulação } & \multicolumn{2}{|c|}{ Produção em bancada } \\
\hline & & $\begin{array}{c}\text { Ácidos graxos } \\
\text { livres }(\%)\end{array}$ & Solvente $(\%)$ & $\begin{array}{c}\text { Ácidos graxos } \\
\text { livres }(\%)\end{array}$ & Solvente $(\%)$ \\
\hline Alimentação & $\mathrm{F}$ & 12,92 & 0,00 & 12,77 & 1,16 \\
\hline Refinado $1^{\circ}$ estágio & R1 & 6,88 & 13,92 & 6,54 & 13,23 \\
\hline Refinado $2^{\circ}$ estágio & R2 & 4,91 & 10,50 & 3,85 & 10,98 \\
\hline Refinado $3^{\circ}$ estágio & $\mathrm{R}$ & 4,36 & 9,65 & 2,83 & 10,03 \\
\hline Extrato $1^{\circ}$ estágio & E1 & 5,67 & 88,32 & 6,24 & 85,42 \\
\hline Extrato $2^{\circ}$ estágio & E2 & 3,73 & 93,28 & 3,51 & 93,28 \\
\hline Extrato $3^{\circ}$ estágio & E3 & 2,28 & 94,32 & 2,81 & 85,42 \\
\hline
\end{tabular}

No primeiro estágio, houve uma concordância entre os valores obtidos na simulação e na produção em bancada. A partir do segundo estágio, observa-se uma diferença maior no conteúdo de ácidos graxos livres nas correntes de refinado. Os resultados de acidez nos refinados do segundo e terceiro estágios são menores na produção em bancada do que na simulação. Nos ensaios para levantamento de dados para modelagem termodinâmica do equilíbrio líquido-líquido, cada amostra passou por apenas uma extração. No teste em bancada, no segundo e terceiro estágios, para os quais a alimentação passa a ser o refinado do estágio anterior, a alimentação não é mais a mesma amostra bruta utilizada para o levantamento dos pontos de equilíbrio do diagrama ternário. Isso pode ter causado as diferenças entre os resultados simulados e os resultados de bancada observados no segundo e terceiro estágio. Tais diferenças são aceitáveis, pois, como pode ser observado, os valores de acidez dos refinados 2 e 3 são menores na produção em bancada do que na simulação.

Nas extrações realizadas para levantamento do diagrama ternário e no primeiro estágio de extração no teste de bancada, formam-se fases intermediárias durante a separação de fases, causadas, possivelmente, pela presença de agentes tensoativos no óleo não degomado. Portanto, no segundo e terceiro estágios esses compostos tensoativos não estão mais presentes no óleo, resultando em apenas duas fases durante a separação de fases. Esse comportamento justifica as diferenças na concentração de ácidos graxos livres nos refinados 
do segundo e terceiro estágios da simulação e do teste de bancada.

A etapa de esterificação foi realizada seguindo-se a mesma metodologia utilizada para a determinação da lei de velocidade. A reação foi conduzida no reator rotativo com banho a $85^{\circ} \mathrm{C}$, contendo a resina Purolite CT275DR, na quantidade equivalente a $20 \%$ da massa de óleo de macaúba e etanol anidro utilizados. A relação mássica óleo/resina foi de 1:1. Após a esterificação e destilação do refinado proveniente do terceiro estágio, obteve-se um óleo com acidez de $0,67 \%$ em massa de ácido oleico, valor ligeiramente superior ao desejado, de $0,50 \%$. Essa não conformidade pode ter ocorrido devido a variabilidade do processo ou pelo aquecimento sofrido durante a destilação, causando a degradação térmica de triacilgliceróis. Esse aumento na acidez pode ser corrigido elevando-se o tempo de residência dos reagentes durante a reação de esterificação ou elevando-se o vácuo na destilação, necessitando-se de uma menor temperatura para a remoção do solvente. 
Journal of Chemical Engineering and Chemistry - JCEC

Revista de Engenharia Química e Química - REQ ${ }^{2}$

ISSN: 2446-9416

doi: https://doi.org/10.18540/24469416020320160061

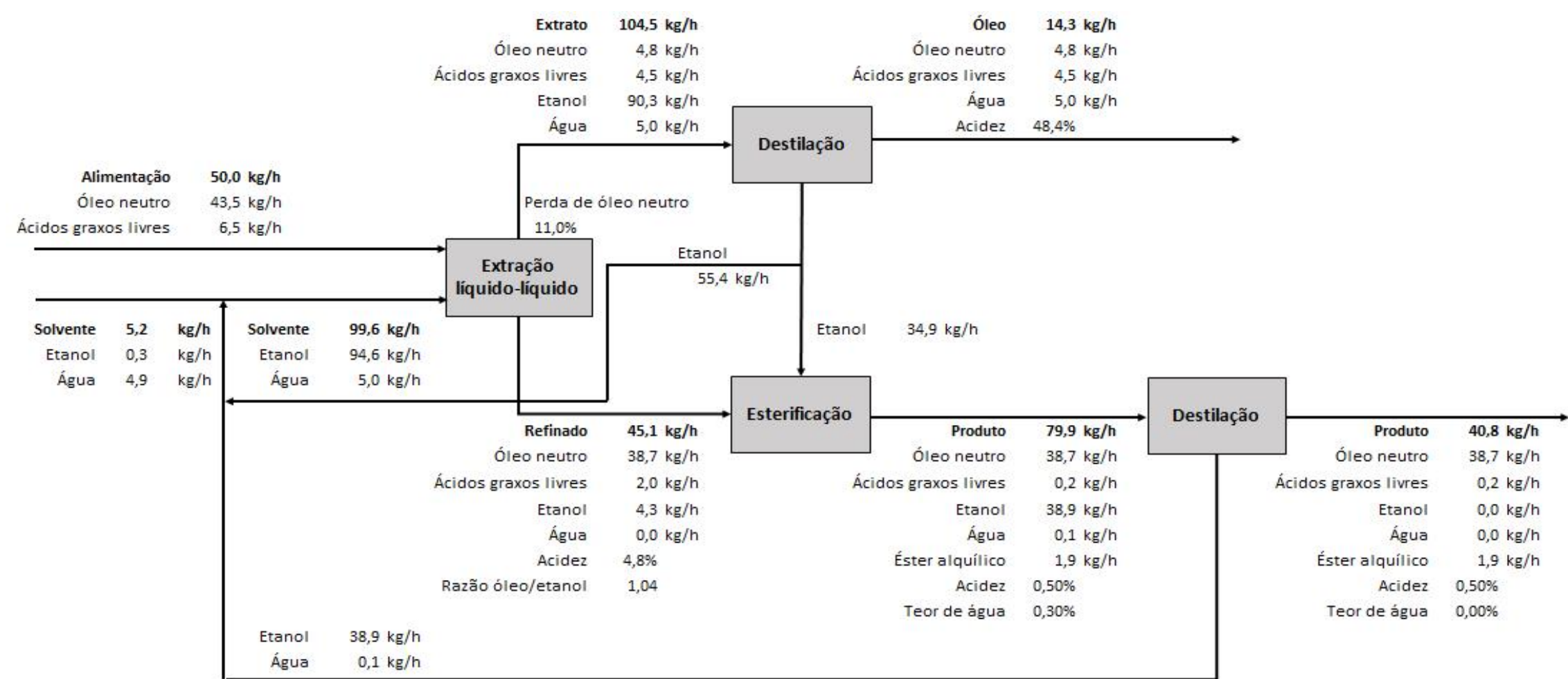

Figura 6 - Proposta de planta de pré-tratamento de óleo de macaúba com acidez inicial de 12,92\% em massa de ácido oleico. 


\section{Journal of Chemical Engineering and Chemistry - JCEC \\ Revista de Engenharia Química e Química - REQ ${ }^{2}$}

ISSN: 2446-9416

\section{CONCLUSÃO}

Com o modelo NRTL do equilíbrio de fases e a lei de velocidade da reação de esterificação, foi possível simular um processo alternativo de desacidificação do óleo de macaúba constituído por uma etapa de extração líquido-líquido para recuperação dos ácidos graxos livres e uma etapa de esterificação por catálise heterogênea para conversão dos ácidos graxos livres remanescentes em ésteres alquílicos. Nesse processo alternativo, a perda de óleo neutro é reduzida, gera-se pouco efluente no processo e o catalisador é de fácil recuperação e reutilização. Na simulação, $50 \mathrm{~kg} \cdot \mathrm{h}^{-1}$ de óleo de macaúba com acidez de $12,92 \%$ são tratados, alcançando-se um $40,8 \mathrm{~kg} \cdot \mathrm{h}^{-1}$ de produto com $0,5 \%$ de acidez. $\mathrm{Na}$ validação em teste de bancada, seguindo-se as mesmas etapas da simulação, alcançou-se um produto com acidez de $0,67 \%$.

Em síntese, pode-se concluir que o processo proposto de desacidificação do óleo de macaúba é tecnicamente viável e pode ser utilizado como pré-tratamento em plantas convencionais de produção de biodiesel. A partir do processo proposto obteve-se um óleo de macaúba neutro, com poucas perdas e com condições brandas de processamento, sem gastos com etapas de tratamento de efluentes e com completa recuperação dos insumos utilizados no processo.

\section{AGRADECIMENTOS}

Agradecemos o apoio financeiro da Agência Nacional do Petróleo, Gás Natural e Biocombustíveis - ANP, da Financiadora de Estudos e Projetos - FINEP - e do Ministério da Ciência e Tecnologia - MCT por meio do Programa de Formação de Recursos Humanos da ANP para o Setor Petróleo e Gás - PRH-ANP/MCT.

\section{REFERÊNCIAS}

ANTONIASSI, R. Desacidificação de óleo de milho com etanol em coluna de discos rotativos (RDC). 1996. 208p. Tese (Doutorado em Tecnologia de Alimentos) Universidade Estadual de Campinas, Campins, SP, 1996.

COSTA, M. A.; SILVA, P. S. C.; VALLE, P. W. P. A. Bioenergia: Cadeia Produtiva e Co-produtos em Minas Gerais. Instituto de Estudos Pró-Cidadania - PRÓCITTÀ/SECTES, Belo Horizonte, 2009.

COSTA, P. A. Integração dos processos de extração líquido-líquido e pervaporação para desacidificação do óleo de macaúba (Acrocomia aculeata). 2012. 75p. Dissertação (Mestrado em Tecnologia de Processos Químicos e Bioquímicos) - Escola de Química, Universidade Federal do Rio de Janeiro, Rio de Janeiro, RJ, 2012.

CVENGROS, J. Physical refining of edible oils. JAOCS. V. 72, n. 10, 1996.

FOGLER, S. H. Elementos de Engenharia das Reações Químicas. Terceira Edição. Rio de Janeiro: LTC, 2002. p. 892.

FRÉ, N. C. D.; MARCÍLIO, N. R. Obtenção de ácidos graxos a partir de borra de neutralização de óleo de soja. VIII Oktoberforum - PPGEQ. Porto Alegre, RS, 2009.

GONÇALVES, C. B.; MEIRELLES, A. J. A. Liquid-liquid equilibrium data for the 
system palm oil + fatty acids + ethanol + water at 318.2 K. Fluid Phase Equilibria. v. 221, p. 139-150, 2004.

JACOBSON, K.; GOPINATH, R.; MEHER, L. C.; DALAI, A. K. Solid acid catalyzed biodiesel production from waste cooking oil. Applied Catalysis B: Environmental. v. 85, p. 86-91, 2008.

LOTERO, E.; LIU, Y.; LOPEZ, D. E.; SUWANNAKARN, K.; BRUCE, D. A.; GOODWIN, J. G. Synthesis of Biodiesel via Acid Catalysis. Ind. Eng. Chem. Res. v. 44, p. 5353-5363, 2005.

LUCIANO, M. A.; PASA, V. M. D.; PIMENTA, T. V.; ANDRADE, M. H. C.; BRITO, M. S. F. Caracterização físico-química do óleo da polpa da macaúba. In: $\sigma^{\circ}$ Congresso Brasileiro de Plantas Oleaginosas, Óleos, Gorduras e Biodiesel. Montes Claros, MG. Agosto de 2009.

NAVARRO, F. M. S.; NAVARRO, R. M. S.; BERTEVELLO, L. C.; TAMBOURGI, E. B. Desacidificação do óleo de farelo de arroz durante o processo de extração líquidolíquido. Estudo da variação de solventes. Exacta. v. 5, n. 1, p. 163-167, 2007.

PERRY, R. H.; GREEN, D. W. Perry's Chemical Engineers' Handbook. $7^{\mathrm{a}}$ ed. McGraw-Hill, 1999.

PIMENTA, T. V. Metodologias de obtenção e caracterização dos óleos do fruto da macaúba com qualidade alimentícia: da coleta à utilização. 2010. 149p. Dissertação (Mestrado em Engenharia Química) - Universidade Federal de Minas Gerais, Belo Horizonte, MG, 2010.

REIPORT, E. C. D.; RODRIGUES, C. E. C.; MEIRELLES, A. J. A. Phase equilibria study of systems composed of refined babassu oil, lauric acid, ethanol, and water at $303.2 \mathrm{~K}$. J.Chem. Thermodynamics. v. 43, p. 1784-1790, 2011.

REZENDE, D. B. Remoção de ácidos graxos livres do óleo da polpa do fruto da macaúba projeto básico visando o acoplamento em usinas de biodiesel. 2015. 135p. Tese de Doutorado (Doutorado em Engenharia Química) - Universidade Federal de Minas Gerais, Belo Horizonte, MG, 2015.

REZENDE, D. B.; SILVA, C. A.; PASA, V. M. D.; ANDRADE, M. H. C. Kinetic Modeling of Esterification Reaction of Free Fatty Acids Present in Macauba Oil Using a Cationic Resin as Catalyst. Journal of Chemistry and Chemical Engineering, v. 9, p. 153$161,2015$.

REZENDE, J. R. Desacidificação de Óleo de Macaúba por Extração LíquidoLíquido, para Produção de Biodiesel. 2009. 61p. Dissertação (Mestrado em Engenharia de Alimentos) - Universidade Estadual do Sudoeste da Bahia, Itapetinga, BA, 2009.

RODRIGUES, C. E. C. Utilização de solvente biorenovável nos processos de extração e desacidificação de óleos vegetais. 172p. Tese de Livre-Docência, Faculdade de Zootecnia e Engenharia de Alimentos da Universidade de São Paulo, Pirassununga, SP, 2011.

SANTORI, G.; DI NICOLA, G.; MOGLIE, M.; POLONARA, F. A review analyzing the industrial biodiesel production starting from vegetable oil refining. Applied Energy. v. 92. p. 109-132, 2012. 


\title{
ALTERNATIVE PROCESS OF DEACIDIFICATION OF MACAUBA OIL (Acrocomia aculeata) AIMING THE BIODIESEL PRODUCTION
}

\begin{abstract}
The availability of low-cost raw material is a key factor for the economic viability of biodiesel production. Together with the raw material, other factors that increase costs in the process of transformation of vegetable oil or animal fat by alkaline transesterification into biodiesel are associated with the purification steps of the raw materials and products. Macauba (Acrocomia aculeata) is an oleaginous palm whose current extraction procedures render it unsuitable for biodiesel production by conventional processes due to its high acidity. In this work, an alternative process is proposed, which is technically feasible and environmentally friendly, for the separation of free fatty acids of the Macauba pulp oil in order to adequate it for biodiesel production by transesterification via homogeneous alkaline catalysis. The process consists of two main steps: liquid-liquid extraction for the recovery of free fatty acids and neutralization of residual fatty acids through esterification. In the simulation, $50 \mathrm{~kg} \cdot \mathrm{h}^{-1}$ of Macauba oil with acidity of $12.9 \%$ are treated, achieving $40.8 \mathrm{~kg} \cdot \mathrm{h}^{-1}$ of a product with acidity of $0.5 \%$. In the validation bench test, following the same steps of the simulation, the acidity achieved in the final product was $0.67 \%$.
\end{abstract}

KEYWORDS: Macauba oil; Esterification, Process simulation, Deacidification, Liquidliquid extraction. 